\title{
Maternal health care services in Nepal: A qualitative perspective based on the socio-ecological model
}

\author{
Mohan Kumar Sharma ${ }^{1,2^{*}}$; Shanti Prasad Khanal'; Ramesh Adhikari2,4; Jib Acharya ${ }^{5}$ \\ ${ }^{1}$ Graduate School of Education (PhD Scholar), Faculty of Education, Tribhuvan University \\ ${ }^{2}$ Center for Research on Education Health and Social Science (CREHSS) Kathmandu, Nepal \\ ${ }^{3}$ Central Department of Health and Population Education, University Campus, TU., Kirtipur \\ ${ }^{4}$ Mahendra Ratna Campus, Kathmandu, Tribhuvan University \\ ${ }^{5}$ Business Development and Health Research, Premium Services Ltd., UK \\ *Correspondence: attrig2019@gmail.com; ORCID: 0000-0002-7600-8223.
}

\begin{abstract}
Nepal has a high Maternal Mortality Rates (MMR) in the South Asian region, partly due to the poor utilization of maternal and child healthcare services. The study aims to explore the influencing factors of maternal and child healthcare services among Nepalese women. Eighteen women, who had seven-days-old-children and those recently accessed maternal and child healthcare practices, were purposively selected. The face-to-face, In-depth-Interview (IDI) was applied to collect the information. The data were thematically analyzed, where Socio-Ecological Model (SEM) was applied as a theoretical framework. The study showed that the factors such as the knowledge of women, perception, and decision-making-autonomy at individual levels influenced maternal and child healthcare-seeking behaviors. Likewise, mothers-in-law and the role of husbands at intrapersonal levels, employment at institutional levels, peers and role of neighbors at community levels, and safe motherhood program at policy levels were significant factors for the utilization of maternal and child healthcare-seekingbehaviors. The negligence of women concerning pregnancy, inadequate health facilities, lack of specialist health workers with advanced equipment, and cultural taboos and beliefs were observed as score barriers for utilization of maternal and child health-seeking behaviors. The research strongly recommends that all women be aware of maternal and child healthcare and health-seeking behaviors at their initial ages.
\end{abstract}

Keywords: Behaviours, maternal health care, Nepal, pregnancy, SEM

\section{INTRODUCTION}

Maternal health is the women's well-being throughout pregnancy, childbirth, and the postpartum period. It includes receiving ANC, PNC check-ups, and delivering at health institutions or being assisted by Skilled Birth Attendants (SBA) at health institutions or homes, which is critical to preventing newborn and maternal deaths (WHO, 2019). Its prime concern is to prioritize women's reproductive health, along with the well-being of newborns (Bhusal, Bhattarai, \& Bhaskar, 2015). 
Nepal is a country with a very high Maternal Mortality Ratio (MMR) (258 per 100,000 live births), which is higher than its South Asian neighbors such as India (174), Bhutan (148), Bangladesh (176), Myanmar (178), Pakistan (178), and Sri Lanka (30) (WHO, 2019). Although there has been a reduction in pregnancy-related mortality in Nepal, there is much more to achieve (MoHP, 2019). Nepal has a low MMR, partly due to the minimum utilization of MHC (Ministry of Health and Population et al., 2018).

In $2016,84 \%$ of pregnant women had at least single ANC contact with a skilled health worker. The percentage of women who had four or more ANC visits increased steadily from $50 \%$ in 2011 to $69 \%$ in 2016. Similarly, the percentage of institutional delivery was improved from $35 \%$ to $57 \%$ in 2011 and 2016, respectively (Ministry of Health, New ERA, \& ICF, 2017).

Nepal is a signatory to the Sustainable Development Goals SDGs.The SDGs target 3 is much more than the promotion, development, and protection of health, which have set ambitious targets for the country to decrease the MMR to 70 per 100,000 live births and neonatal mortality to 12 per 1,000 live births and to achieve coverage of $90 \%$ for four ANC visits, institutional delivery, SBA delivery, and three PNC check-ups by 2030 . Nepal needs to reduce its MMR by at least $7.5 \%$ annually to attain this ambitious target, addressing severe inequities in maternal health services (Shrestha, 2019). Nepal has been applying for the safer motherhood program since 1997 with the broad aims of reducing maternal and neonatal morbidity and mortality rates and improving maternal and neonatal health (Ministry of Health et al., 2017). As per the Department of Health Services (DHS) of Nepal, the safe motherhood program includes strategies focused on birth preparedness, ANC check-ups, and institutional delivery that reduce the hazards of complications during pregnancy and childbirth and deal with the issues allied with mortality and morbidity (DOHS, 2018). In 2005, Nepal introduced the Aama Program (Maternity Incentive Scheme), aiming to reduce financial barriers for women who seek institutional delivery and are given a case incentive of Nepali Rupees (NRs) 3,000, (NRs) 2,000, and (NRs) 1,000 in Mountain, Hill, and Terai districts respectively, with an additional (NRs) 8,00 to those women who complete four ANC visits per national protocol Family Health Division (FHD) (FHD, 2018). To date, maternal health-seeking behavior is a complex phenomenon in Nepal. Thus to improve it, all births deliveries should do with skillful health staff in the health institutions.

Regarding maternal health care, several quantitative and a few qualitative studies have been conducted in Nepal Shahabuddin et al. (2019), which identified socio-demographic covariates that influenced maternal health-seeking behavior in diverse areas of Nepal. However, as far as our knowledge is concerned, there are no recorded, published qualitative articles applying the Socio-Ecological Model (SEM) approach, which digs out the different influencing factors; interpersonal, intrapersonal, community, institutional, and health policy to use of maternal health-seeking behavior (Shahabuddin, Delvaux, Nostlinger, Sarker, \& De Brouwere 2017). This research analyzes maternal health care behavior (four ANC visits, as per national protocol in the $4^{\text {th }}, 6^{\text {th }}, 8^{\text {th }}$, and $9^{\text {th }}$ month of pregnancy, institutional delivery, and PNC check-ups within seven days for women during their pregnancy) of Nepalese women, using Socio-Ecological Model (SEM) approach (Sharma, Khanal, \& Adhikari 2020). 


\section{MATERIALS AND METHODS}

\section{Research design}

This is qualitative exploratory research performed in April 2020, in Kathmandu Nepal. As research followed qualitative exploratory research design, subjectivist epistemology and relativist ontology Sharma et al. (2019) is its philosophical paradigm constructed within the individual experience.

\section{Data collection tools}

Qualitative data were collected through the use of IDIs. Initially, bases were formulated on research objectives reviewed by the 'experts' Zohrabi (2013) and finalized by the panel of experts (Bolarinwa, 2015). The tools were trailed to the participants at their convenient place and time directly. Before that, they were informed about the study objectives and consequences. After their consent, an interview was conducted. They were not provided with any type of compensation for participating in the research.

\section{Sample and sampling techniques}

The participants were selected based on a purposive sampling method (Koul, 1984). Researchers used this technique carefully based on the study purpose to expect each participant to have unique, fresh, and rich information of value to the maternal health-seeking behavior. The member of the accessible population was not interchangeable. The sample size is determined by the data saturation (Suen, Huang, \& Lee 2014). In which, researchers felt that the data saturation is eighteen participants $(\mathrm{n}=18)$ for this study. The participants were purposively selected who had a child within seven days. The face-to-face interview was conducted with the participants using an open-ended questionnaire.

\section{Ethical considerations}

Before the study, the researcher has obtained oral consent from each participant. Informed consent was orally taken from all participants, in which a description of the study purpose, the participant's role in the research, procedures to be followed, benefits, risks, and confidentiality, expected duration of participation, right to refuse, the approximate number of study participants, and contact information was presented. The institutional permission was not obtained for the study because we thought these issues had less likely importance to obtain ethical consideration.

\section{Data collection, handling, and analysis}

The data were collected through the application of in-depth interview guidelines. There were no incentives such as money or any goods offered to the participants who agreed to be involved in the study. All the collected interview forms were carefully re-checked by the principal investigator. The researcher has transcribed all the data with the support of senior researchers. The transcriptions were carefully re-checked several times to reduce the duplications, missing and niceness. Further, the transcriptions were carefully coded, categorized, and thematized manually at various times and made a final form (see Table 1). At the same time, it followed a thematic analytical framework, which was analyzed based on the SEM approach and various factors such as individual, interpersonal, community, institutional, and policy level. 
Table 1: Summary of making codes, categories, and themes

\begin{tabular}{|c|c|c|}
\hline Codes & Categories & Themes \\
\hline $\begin{array}{l}\text { Risk on early adolescent pregnancy } \\
\text { The decision for child adoption }\end{array}$ & $\begin{array}{l}\text { The decision for child adoption } \\
\text { in adolescent } \\
\text { Knowledge and perception }\end{array}$ & $\begin{array}{l}\text { Individual-level } \\
\text { factors }\end{array}$ \\
\hline $\begin{array}{l}\text { Overlook on pregnancy period } \\
\text { Perceived risk on pregnancy by } \\
\text { several health problems } \\
\text { Maternal and child healthcare }\end{array}$ & $\begin{array}{l}\text { Negligence on pregnancy } \\
\text { Concerned on pregnancy and } \\
\text { maternal and child healthcare }\end{array}$ & \\
\hline $\begin{array}{l}\text { Family support in maternal and child } \\
\text { healthcare, } \\
\text { Special support of mothers-in-law } \\
\text { Feeling shame to disclose about } \\
\text { pregnancy. }\end{array}$ & $\begin{array}{l}\text { Family support, especially } \\
\text { mothers-in-law } \\
\text { Shame to disclose about } \\
\text { pregnancy }\end{array}$ & $\begin{array}{l}\text { Intrapersonal level } \\
\text { factors }\end{array}$ \\
\hline $\begin{array}{l}\text { Inadequate infrastructure at health } \\
\text { institutions } \\
\text { Lack of skilled maternal and child } \\
\text { healthcare services and Gynecologist } \\
\text { Institutional support/role during } \\
\text { pregnancy }\end{array}$ & $\begin{array}{l}\text { Inadequate health infrastructure, } \\
\text { health workers, and } \\
\text { transportation in rural health } \\
\text { institutions } \\
\begin{array}{l}\text { Institutional support during } \\
\text { pregnancy }\end{array}\end{array}$ & $\begin{array}{l}\text { Institutional } \\
\text { Factors }\end{array}$ \\
\hline $\begin{array}{l}\text { Community Levels factors } \\
\text { Role of Female Community Health } \\
\text { Workers (FCHVs) } \\
\text { Role of neighbors }\end{array}$ & $\begin{array}{l}\text { Role of neighbors during } \\
\text { pregnancy } \\
\text { Role of FCHVs on pregnancy }\end{array}$ & $\begin{array}{l}\text { Community Levels } \\
\text { factors }\end{array}$ \\
\hline $\begin{array}{l}\text { Reduces the potential health risks } \\
\text { during pregnancy } \\
\text { Insufficient allowance for pregnancy }\end{array}$ & Condense the risk of pregnancy & $\begin{array}{l}\text { National Levels } \\
\text { Health Policy }\end{array}$ \\
\hline
\end{tabular}

\section{Theoretical framework}

The SEM is a framework that relates to theory and considers the multiple stages of a communal scheme, including the interactions between persons and all surroundings within the SEM system. The SEM facilitated the investigation of mothers' experiences in various levels that influence their families, organizations/institutional, community, and policy levels' contexts that all work on different levels (Figure 1) to influence maternal health-seeking behaviors. For instance, personal interaction and family support assist MHC behavior. Further, interpersonal communication and institutional affiliation may impact MHC differently for women. The SEM approach was applied in this study to elaborate on women's MHC perception at different levels. 


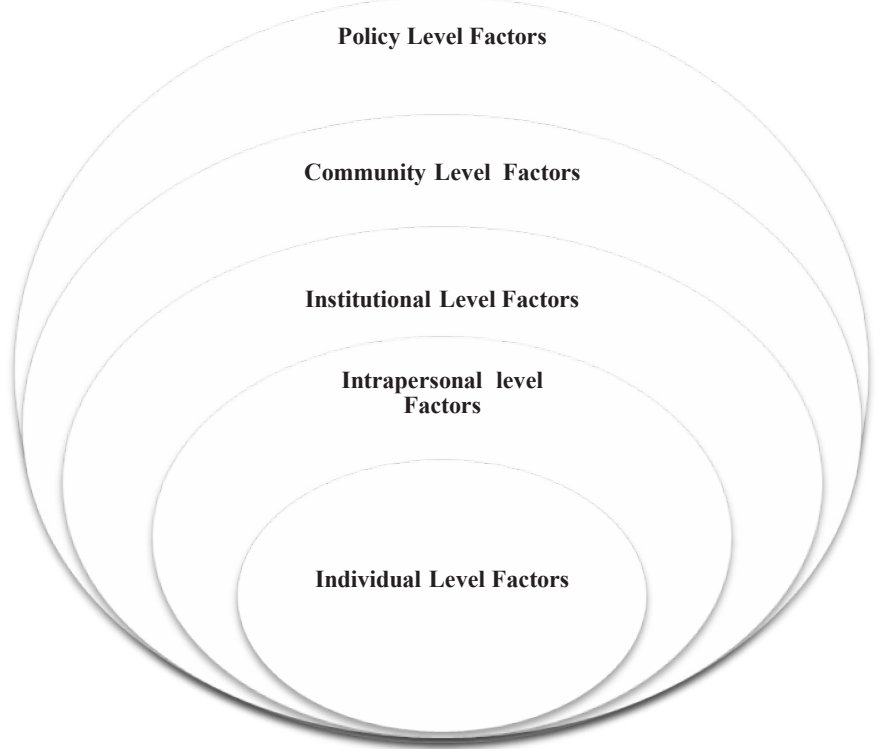

Figure 1: The theoretical framework of the study (Mcleroy, Bibeau, Steckler, \& Glanz, 1988)

The figure illustrates the SEM framework, which includes the five levels; the individual/ interpersonal sphere, the intrapersonal sphere, the organizational/institutional sphere, the community sphere, and the policy sphere (Mcleroy et al., 1988). This framework was adopted from Mcleroy et al. (1988) to explain women's perception of maternal healthcare-seeking behavior from the five different levels closely related to the SEM approach.

\section{RESULTS}

The below sections outline the key findings of the research. The findings were thematized in five separate subjects: Interpersonal, Intrapersonal, Institutional, Community, and Policy level factors, and analyzed based on SEM to explore maternal health-seeking behavior in the background of Nepalese women.

Participants were between the ages of 16-34 years of age, completed secondary level (academic degrees) to master's degrees. Twelve $(\mathrm{n}=12)$ women had completed their four ANC checked-up about the maternal health care services. All participants $(n=18)$ had delivered their babies at the hospital and had the PNC assessments adequately.

\section{Individual-level factors}

Under the SEM approach, the following individual-level factors have consisted of biological and individual history issues, which determine the women's maternal and child healthcare behavior. These individual factors, age, education, skill-training, social-emotional learning, and income, are the determinants of maternal health-seeking performance.

Almost all participants were aware of the pregnancy. They perceived this period from the various aspects; something developing within their womb which needs a lot of care and precautions; a potential maternal risk like death and opportunity; to give birth to a new baby. A woman, who had open-heart surgery before six years, never imagined having a baby because of potential health risks to both mothers and children. After the close consultation and 
recommendation of a Gynecologist and Cardiologist, she adopted a baby. She explained her experiences like this;

"Initially, I am not sure whether I should adopt a baby because I am a chronic heart patient, had open-heart surgery, and taking regular medicines. I adopted a baby in close consultation with both specialists; Gynecologist and Cardiologist. I still would not have adopted a baby if Gynoecia and Cardiac did not recommend meeting a great opportunity to have a child-like me as a chronic heart patient despite having its potential negative consequences." (IDI: 29-year-old-participant, IDI)

Getting married and giving birth to a baby at an early adolescent age invites several risks to maternal health. If the girls are not well prepared physically, mentally, and emotionally to adopt the baby is more likely to be maternal death. The below-given quotes clarify the statement.

"This is my fifth child. All children (four) were miscarriages which delivered at home. So, at this time, I was hospitalized two weeks before the delivery date. I have got married at 14 years of age. At that time, my body was not physically fit and matured enough to have a baby. These days, I realized that babies should not be borne at an early adolescent age even if I got married." (IDI:19-year-old participant)

This verbatim response showed that women were aware of maternal health, whether to plan the baby or not, even though they have chronic diseases. During the discussion, the participants have explored what they had further experienced and were conscious about the consequences of early adolescent pregnancy and home delivery.

Almost all the participants agreed that the frequency of ANC visits and hospital deliveries was crucial to providing quality maternal health care. Of the total number of participants, twelve participants were found who received ANC checked-up four times, and all cases $(n=18)$ were delivered at the hospital. It showed the importance of the ANC check-up and institutional delivery.

"It is safe to go to the hospital for specialist services; Gynecologist has better knowledge. They coordinate to other specialists like Cardiologist, Neurologist, and many more if the patient has multiple health problems." (IDI: 31-year-old participant with diabetes and thyroid conditions)

Fewer respondents did not follow ANC visits properly due to their negligence and or overconfidence. In response to why four times ANC visits are crucial for the child and mother, a 24 years old mother revealed accordingly:

"I knew that I become pregnant when my menstruation period stops and I thought it was unnecessary to go to the hospital for a check-up because I did not feel any complications. Thus, I visited the hospital only during the last trimester of pregnancy. Unfortunately, my child had human excreta (feces) within the womb. Now he is at Neonatal Intensive Care Unit (NICU), and I am at home." (IDI: 24-year-old woman)

It is unfortunate; knowledge is insufficient, which is an implication in real life that weighted more. There are two main key reasons behind this: mothers' negligence and another one, mothers, did not feel reluctant to share information regarding their pregnancies. 


\section{Intra-personal level factors}

Intra-personal factors comprise relationships with others and effects on social identity. The interrelationships with family members' influence and emotional support are renowned contributing factors for maternal health care behavior.

A supportive environment and good relations are essential, especially between mothers-in-law and daughters-in-law during pregnancy. The mothers-in-law are considered the most experienced persons to share and advice about maternal and child healthcare issues. Respondents mentioned that their female family members play a decisive role in MHCB.

"My mother-in-law took me to the hospital for the pregnancy check-up." (IDI: 19-yearold woman)

"Mother or mother-in-law took more responsibilities and authorities especially during pregnancy to take care and guide to daughter or daughter-in-law in the belief that they understand women's health issues, including childcare." (IDI: 18-year-old woman)

All participants mentioned that they participated in household decision-making, including maternal and child healthcare issues. Most decisions were made either by the agreement of spouses or senior members of the households, especially the father and mother or the mothersin-law and fathers-in-law.

"Most married women were unwilling to have a child instantly just after getting married and did not consult with any other persons. However, family members always emphasized or encouraged the newly married to conceive instantly. Furthermore, the married women decide to have only one child." (IDI: 32-year-old respondent)

This symbolizes that, in some cases, the individual's decision is influenced by family factors. The majority of the respondents indicated they had decision-making autonomy towards their healthcare issues, including maternal and child health. The participants who made four ANC visits at health institutions responded that they visited the health institutions based on the healthworkers advice. The situation and ignorance embedded within women's health-seeking behaviors strongly influenced the shaping of the MHSB.

"I did not visit the hospital during my first trimester of pregnancy due to the unavailability of female health workers because of existing social norms and values that do not disclose pregnancy issues to the male in the absence of the husband. At the same time, my husband was out of the home. I visited the hospital only after the pressure by relatives and peers with another pregnant woman who had a husband." (IDI: 18-yearold woman)

Despite knowing of MHCB, women will not visit health institutions due to negligence on pregnancy issues. They were not prohibited; either social norms or family members only feel shy to expose that she is pregnant with male health workers. Thus, it is the case that respondents do not realize the convenience of sharing their reproductive problems with male health workers.

\section{Institutional levels factors}

The institutional level factors concern; how to do organizational characteristics can be used to support behavioral changes. Voluntary organizations such as neighborhoods and professional associations are essential sources and transmitters of social norms and values and provide the 
opportunity to build social support for health-related behavior formation. Some organizations have been supporting maternal healthcare activities, particularly in their worksites.

"I work only five hours at my office during pregnancy and offered supplementary food in the cafeteria to encourage staff like me." (IDI:32-year-old woman)

In some cases, the absence of female health workers has significant effects on discouraging women from seeking maternal healthcare services. Furthermore, the poor infrastructures, nonavailability of maternal require equipment, and lack of transportation facility as an ambulance at the time of emergency are discouraging factors to utilize the MHCB.

"There has no minimum standard infrastructure and health facility along with Gynecologist for delivery service in our rural health post. So, it compelled us to come to this hospital despite many discomforts; the lock-down, financial crisis, no vehicle (ambulance). Suppose, we had specialist services in our local health institutions with appropriate maternal and child healthcare equipment, in that case, we have no compulsion to search big hospitals during the COVID-19 pandemic." (IDI: 30-year-old woman)

Health organizations with poor infrastructure and low-quality child and maternal health services are the barriers to MHCB utilization. This is evidence that all health posts' health services are not as good as they should be, especially in rural areas of Nepal.

\section{Community-level factors}

The female community health workers significantly encouraged pregnant women to seek healthcare facilities for their ANC/PNC visits and delivery. Most women responded that they received maternal and child healthcare information from the community workers, where only a few revealed from the FCHV. Respondents from the remote areas mentioned that they obtained information from the FCHV regarding maternal and child health care, including the importance of ANC, PNC, and deliveries at health facilities.

"After my third ANC visits, one of the FCHV has suggested that to visit the hospital which equipped Gynecologist who could minimize the potential health hazards of both child and mother, and I did thoroughly." (IDI: 26-year-old woman)

In the village, pregnant women and neighbors often go to the nearest health facilities for their ANC/PNC check-up when it is far from their villages. On the other hand, most pregnant women prefer to visit the health facilities with their husbands in the countryside. Only they prefer their family members in the absence of the husband.

"I usually go to the health facilities for ANC check-ups with neighbor women with whom my delivery date was very close." (IDI:20-year-old woman)

"I have never been in the hospital without my husband except once. At that time, he was out of the country due to occupational engagement." (IDI:30-year-old woman)

This statement showed that family members have a decisive role during pregnancy, even husband is present.

\section{Public health policy}

The Government of Nepal (GoN) provisions different health policies for their civic. Safe Motherhood Program is one of the policies under which the GoN provides cash incentives to women who use maternal health services, including ANC/PNC and the delivery facilities at the 
health institutions. Despite delivering at homes, women are reported going to a health facility to receive money and clothes for babies.

"I came to the hospital to have the child delivered because it provides money to the mothers and clothes to the children, and it is free. Besides that, it is a safe and reliable place to minimize the health risks of mother and baby." (IDI:26-year-old woman)

The government hospitals provide NRs. 500 to 1000 as incentive per delivery, NRs. 1000 is given in the hilly region and NRs. 500 in Terai, respectively. The motivation for the maternal health service uptake is a motivational factor that could not be a sustainable and good idea because people go to the hospital just for services. Although public policy can not address the cash incentive and other facilities to utilize the MCHS services by the people, the institutional delivery increases the quality of health care to prevent avoidable deaths and debilitating morbidities. The main strategies are to improve the quality of services, well-equipped health facilities, roll out maternal and prenatal death, and surveillance reviews.

"Free delivery does not address the transportation costs; other required drugs and equipment for delivery, and hospital ward charges." (IDI: 29-year-old woman)

It is the representative voice of civic that nation should include overall expenders while on delivering. This evidence showed that government policy can still not properly encourage the utilization of maternal healthcare services.

\section{DISCUSSION}

This research found that at the individual level, knowledge, awareness, decision-making autonomy, and personal perception towards maternal and child healthcare systems were perceived as influential positive factors to adopt it. In the same line of our findings, a study conducted by Kusumayati \& Nakamura (2007) in Indonesia sought maternally and child healthcare behavior closely associated with better maternal knowledge, including ANC/PNC, regular health check-ups, and skilled birth attendance (Kusumayati \& Nakamura, 2007). A similar study conducted by Matsumura \& Gubhaju (2001) has found that low decision-making autonomy, poor access or distance of health post, and poor awareness level were barriers to maternal and child healthcare services (Matsumura \& Gubhaju, 2001). Similarly, the same study carried out by Matsumura \& Gubhaju (2001) found that women's employment was negatively associated with maternal and child health services. It may be due to heavy work pressure because most women in Nepal live in rural areas and are engaged in agriculture. The workload does not likely give women time away from their work and focus on their health issues. Also, employed women have faced the double burden of work-loads, both in their home and outside. Therefore, they would not have the time to seek care, making them less likely to use the available healthcare services. In contrast, our research found that it does not explore significant outcomes whether women were employed or remained housewives. They both have fully supported from the entire family members when they are pregnant.

At the intrapersonal level, this research found that the environment surrounded by family members and peer groups influenced women's maternal health behavior. Almost all reported that all family members were referred for institutional delivery than home despite full support of family; even their family member was a doctor. In contrast to our findings, women with low decision-making autonomy almost always followed their mothers-in-law's plans for their pregnancy and delivery care needs (Simkhad, Porter, \& van Teijlingen, 2010). Further, in line with other studies conducted in Nepal Shrestha, Banu, Khanom, Ali, \& Devkota (2012), our 
findings showed that mothers-in-law were considered the most experienced and skillful person concerning maternal and child healthcare services and providers and counselors where men were the obedient ones. Some other studies conducted in Nepal by Anwaret, Kalim, and Koblinsky (2009) revealed that wealth, husband's education, and good communication with the spouse played a significant role in improving antenatal care and delivery services (Anwar et al., 2009).

At the institutional level, this research found that the low accessibility of health institutions and maternal health service providers, especially in rural areas, though might not necessarily translate into increased utilization of the MHSB (Banstola, 2017). The previous studies carried out by Dutta and Sengupta (2018) and Glei and Goldman (2003) indicated in line with our findings that parameters of geographical factors, distance, and road conditions have no significant effects on shaping the MHSB amongst the studied population. In 2006, Filippi and team had conducted a similar study and stated that there are many reasons likely to be contributing to the low rates of utilization of maternal and child healthcare services, poor physical access to health care services due to difficult geographical locations, limited health infrastructures, and limited specialist services in rural areas of the developing countries (Filippiet, Ronsmans, Campbell, Graham, \& Osrin, 2006). Controversially, our research indicates that despite lock-down, limited financial resources, including free ambulance services for baby delivery, women have approached the hospital from different areas searching for quality maternal and child healthcare services.

As a result, in search of quality maternal and child healthcare services, most women came to the capital city from different country areas despite the lock-down and many other difficulties. In this context, Filippi et al. (2006) study seem similar in many developing countries. The rural postings go vacant due to inadequate facilities, i.e., remuneration, low prestige, inadequate health and education facilities for babies, social isolation, and lack of health facilities.

At the community level, this research found out that the role of community health workers and neighbors significantly influenced the proper utilization of maternal and child healthcare services such as ANC/PNC check-ups and institutional delivery. Further, this study showed that the community and location of health care services promote healthy behaviors. The importance of the community is that its implications for the development and of health promotion. In the same line with the findings of this study, Kusumayati and Nakamura (2018) have revealed that trained health workers should provide maternal and child healthcare services to the people who come to utilize the services.

At the policy level, the researcher of this study has found that the government's initiative program and quality of care influenced maternal and child health-seeking behaviors. These findings are as similar to Shahabuddin et al. (2019). The quality of health services in the health posts, positive attitudes of healthcare service providers, and government programs directly influenced maternal and child health-seeking behavior of adolescent girls. In our research, some mothers sought that the Safer Motherhood Programme provides cash and clothes initiatives to use maternal and child healthcare services, including ANC and PNC check-ups and institutional delivery. In line with our findings, some studies conducted by Edu et al. revealed that many more people now come to the health centers for ANC, PNC check-ups and deliveries because it is entirely free (Edu, Agan, Monjok, \& Makowiecka, 2017). In 2017, Edu et al. stated that the cost of items required for delivery was not covered by the free MHC service, a significant barrier to the health facilities. 
Interestingly, all mothers are searching for quality maternal and child healthcare services with specialists and modern equipment. Similar studies conducted by Islam et al. in Bangladesh showed that the shortage of staff and resources, inadequate infrastructures, and the unavailability of trained female medical personnel impeded women from seeking quality maternal and child healthcare services (Islam, Rahman, Halim, Eriksson, \& Dalal, 2015). Focusing on the policy level factors, all respondents stated that they visited hospitals, especially in the search for quality services than cash incentives and clothes.

\section{CONCLUSION}

Several factors influence the maternal and child healthcare-seeking behaviors; i) in interpersonal level, knowledge of women concerning MCHB, perception to the service providers, decision making autonomy, ii) an intrapersonal level, the role of family members, especially mothers-inlaw and husbands, iii) in institutional occupation of the women where they are engaging, iv) in community-level the role of neighbors and peers where they reside in communities, and use a small case in policy level the existing policy for ANC and PNC check-ups and delivery for pregnant women at the policy levels have significant effects on maternal and child healthcareseeking behaviors. Nevertheless, the lack of knowledge, negative attitudes, and overlook on pregnancy period, poor health infrastructure, and inadequately trained health workers harmfully impacted the Nepalese women's maternal and child healthcare behavior. More health facilities, especially in remote areas, needed to be constructed with medicinal tools, drugs, and skillful health workers.

\section{REFERENCES}

Aryal, K. K., Sharma, S. K., Khanal, M. N., Bista, B., \& Steffen, M. M. (2019). Maternal Health Care in Nepal: Trends and Determinants. DHS Further Analysis Reports No. 118. Rockville, Maryland, USA: ICF. Retrieved from https://dhsprogram.com/pubs/pdf/FA118/FA118.pdf

Anwar, I., Kalim, N., \& Koblinsky, M. (2009). Quality of Obstetric Care in Public-sector Facilities and Constraints to Implementing Emergency Obstetric Care Services: Evidence from High- and Low-performing Districts of Bangladesh. Journal of Health, Population and Nutrition, 27(2): 139-155. Retrieved from https://www.jstor.org/stable/23499520

Banstola, A. (2017). The Current State of Maternal Health in Nepal. Maternal Health Task Force Blog Post. Retrived from https://www.mhtf.org/2017/12/29/the-current-state-ofmaternal-health-in-nepal/

Bhusal, C. K., Bhattarai, S., \& Bhaskar, R. K. (2015). Maternal health in Nepal: Progress, challenges, and opportunities. International Journal of Medical and Health Research, 1(3): 68-7.

Bolarinwa, O. A. (2015). Principles and methods of validity and reliability testing of questionnaires used in social and health science researches. The Nigerian Postgraduate Medical Journal 22(4):195-201. doi: doi: https://doi.org/10.4103/1117-1936.173959

DoHS, (2018). Annual Report 2075/76 (2018/19). Retrieved from https://dohs.gov.np/wpcontent/uploads/2020/11/DoHS-Annual-Report-FY-075-76-.pdf 
Dutta, P., \& Sengupta, B. (2018). Barriers of Maternal Health Seeking Behavior: A Bayesian Analysis. Journal of Women's Health Care, 7(4): 1-12. doi: https://doi.org/10.4172/2167$\underline{0420.1000439}$

Edu, B. C., Agan, T. U., Monjok, E., \& Makowiecka, K. (2017). Effect of Free Maternal Health Care Program on Health-seeking Behavior of Women during Pregnancy, Intra-partum and Postpartum Periods in Cross River State of Nigeria: A Mixed Method Study. Macedonian Journal of Medical Sciences, 5(3): 370-382. doi: https://doi.org/10.3889/oamjms.2017.075.

Family Health Division, (2018). Aama Circular 2075. Government of Nepal, Ministry of Health and Population. Retrieved from http://fhd.gov.np/images/notice/Aama_Circular_2075.pdf. 42

Filippi, V., Ronsmans, C., Campbell, O. M R., Graham, W. J., \& Osrin, D. (2006). Maternal health in poor countries: The broader context and a call for action. Lancet, 368(9546):1535-41. doi: https://doi.org/10.1016/S0140-6736(06)69384-7.

Glei, D. A., \& Goldman, N. (2003). Utilization of care during pregnancy in rural Guatemala: Does obstetrical need matter? Social Science \& Medicine, 57(12): 2447-2463. doi: https://doi.org/10.1016/S0277-9536(03)00140-0

Islam, F., Rahman, A., Halim, A., Eriksson, C., \& Dalal, K. (2015). Perceptions of health care providers and patients on quality of care in maternal and neonatal health in fourteen Bangladesh government healthcare facilities: A mixed-method study. BMC Health Services Research, 15(237): 1-9. doi: https://doi.org/10.1186/s12913-015-0918-9

Koul, L. (1984). Methodology of educational research (4 ${ }^{\text {th }}$ ed.). Ansari Road New Delhi110002: Vikas Publishing House Pvt. Ltd.

Kusumayati, A., \& Nakamura, Y. (2007). Increased Utilization of Maternal Health Services by Mothers Using the Maternal and Child Health Handbook in Indonesia. Journal of International Health, 22(3): doi: 143-151. https://doi.org/10.11197/jaih.22.143

Matsumura, B. M., \& Gubhaju, B. (2001). Women's status, household structure and the utilization of maternal health services in Nepal. Asia-Pacific Population Journal, 16(1): 23-44. doi: https://doi.org/10.18356/e8a4c9ed-en

McLeroy, K. R., Bibeau, D., Steckler, A., \& Glanz, K. (1988). An Ecological Perspective on Health Promotion Programs. Health Education Quarterly, 15(4): 351-377. doi: https://doi.org/10.1177/109019818801500401

Ministry of Health, New ERA, and ICF (2017). 2016 Nepal Demographic and Health Survey Key Findings. Kathmandu, Nepal: Ministry of Health Nepal. Retrieved from https://nepal.unfpa.org/sites/default/files/pubpdf/NDHS\%202016\%20key\%20findings.pdf

Ministry of Health, Nepal, New ERA, and ICF(2017). Nepal Demographic and Health Survey 2016. Kathmandu,Nepal: Ministry of Health, Nepal. Retrieved from https://drive.google.com/file/d/1SLRT54QPqair4oWK67Q6c_2qG_WuRF--/view

Ministry of Health and Population, New ERA, UNICEF, EU, USAID, and CDC (2018). Nepal National Micronutrient Status Survey, 2016. Kathmandu, Nepal: Ministry of Health and 
Population, Nepal. Retrieved from https://www.unicef.org/nepal/reports/nepal-nationalmicronutrient-status-survey-report-2016

Shahabuddin, A., Delvaux, T., Nostlinger, C., Sarker, M., \&De Brouwere, V. (2017). Exploring Maternal Health Care-Seeking Behavior of Married Adolescent Girls in Bangladesh: A Social-Ecological Approach.PloS One, 12(1), e0169109. doi: https://doi.org/10.1371/journal.pone.016910

Shahabuddin, A., Delvaux, T., Nostlinger, C., Sarker, M., \&De Brouwere, V. (2019). Maternal healthcare-seeking behaviour of married adolescent girls: A prospective qualitative study in Banke District, Nepal. PloS One, 14(6), e0217968. doi: https://doi.org/10.1371/journal.pone.0217968

Sharma, M. K., Khanal, S. K., \& Adhikari, A. (2019). Menstrual Hygiene Management Among Girls in Rural Schools of Rukum Nepal. EC Gynaecology, 8(10): 962-970. Retrieved from https://www.researchgate.net/publication/336086380

Shrestha, S. K., Banu, B., Khanom, K., Ali, L., \& Devkota, B. (2012). Changing trends on the place of delivery: Why do Nepali women give birth at home? Reproductive Health, 9(25). doi: https://doi.org/10.1186/1742-4755-9-25

Shrestha, R. (2012). "Maternal Mortality in Nepal: Addressing the Issue." Inquiries Journal, 4(10), 1-4. Retrieved from http://www.inquiriesjournal.com/articles/708/ maternal-mortality-in-nepal-addressing-the-issue

Simkhada, B., Porter, M. A., \& van Teijlingen, E. R. (2010). The role of mothers-in-law in antenatal care decision-making in Nepal: A qualitative study. BMC Pregnancy and Childbirth 10(34): 1-10. doi: https://doi.org/10.1186/1471-2393-10-34

Suen, Lee-Jen W., Huang, Hui-man, \& Lee, Hao-Hsien (2014). A Comparison of Convenience Sampling and Purposive Sampling. The Journal of Nursing 61(3):105-111.doi: https://doi.org/10.6224/JN.61.3.105

World Health Organization. (2019).Trends in maternal mortality 2000 to 2017: Estimates by WHO, UNICEF, UNFPA, World Bank Group and the United Nations Population Division: Executive summary. World Health Organization. Retrieved from https://apps.who.int/iris/handle/10665/327596.

Zohrabi, M. (2013). Mixed method research: Instrumentsvalidity, reliability and reporting findings.Theory and Practice in Language Studies, 3(2): 254-262. doi: https://doi.org /10.4304/tpls.3.2.254-262 